\title{
Detection of potentially relevant extracolonic and colorectal findings at CT colonography in a low-risk symptomatic patient population
}

Citation for published version (APA):

Netz, F. R. S., Pickhardt, P. J., Heijnen, M. L. G. J., \& Simons, P. C. G. (2017). Detection of potentially relevant extracolonic and colorectal findings at CT colonography in a low-risk symptomatic patient population. Abdominal Radiology, 42(12), 2799-2806. https://doi.org/10.1007/s00261-017-1221-5

Document status and date:

Published: 01/12/2017

DOI:

10.1007/s00261-017-1221-5

Document Version:

Publisher's PDF, also known as Version of record

Document license:

Taverne

Please check the document version of this publication:

- A submitted manuscript is the version of the article upon submission and before peer-review. There can be important differences between the submitted version and the official published version of record.

People interested in the research are advised to contact the author for the final version of the publication, or visit the DOI to the publisher's website.

- The final author version and the galley proof are versions of the publication after peer review.

- The final published version features the final layout of the paper including the volume, issue and page numbers.

Link to publication

\footnotetext{
General rights rights.

- You may freely distribute the URL identifying the publication in the public portal. please follow below link for the End User Agreement:

www.umlib.nl/taverne-license

Take down policy

If you believe that this document breaches copyright please contact us at:

repository@maastrichtuniversity.nl

providing details and we will investigate your claim.
}

Copyright and moral rights for the publications made accessible in the public portal are retained by the authors and/or other copyright owners and it is a condition of accessing publications that users recognise and abide by the legal requirements associated with these

- Users may download and print one copy of any publication from the public portal for the purpose of private study or research.

- You may not further distribute the material or use it for any profit-making activity or commercial gain

If the publication is distributed under the terms of Article $25 \mathrm{fa}$ of the Dutch Copyright Act, indicated by the "Taverne" license above, 


\title{
Detection of potentially relevant extracolonic and colorectal findings at CT colonography in a low-risk symptomatic patient population
}

\author{
F. R. S. Netz, ${ }^{1}$ P. J. Pickhardt, ${ }^{2}$ M. L. G. Janssen Heijnen, ${ }^{3,4}$ P. C. G. Simons ${ }^{1}$ \\ ${ }^{1}$ Department of Radiology, Viecuri Medical Centre, Venlo, The Netherlands \\ ${ }^{2}$ Department of Radiology, University of Wisconsin School of Medicine \& Public Health, Madison, USA \\ ${ }^{3}$ Department of Epidemiology, Viecuri Medical Centre, Venlo, The Netherlands \\ ${ }^{4}$ Department of Epidemiology, GROW School for Oncology and Development Biology, Maastricht University Medical Centre, \\ Maastricht, The Netherlands
}

\begin{abstract}
Purpose: CT colonography (CTC) is a widely accepted examination tool for detection of colorectal lesions but evidence of the proportions of relevant extracolonic findings $(\mathrm{ECF})$ in a large symptomatic but still relatively low-risk cohort is lacking, as well as their relationship to symptoms, age, and sex.

Methods: All patients $(n=3208)$ with colorectal symptoms, imaged between January 2007 and September 2016 with first-time CTC, were retrospectively selected. The majority $(96.7 \%)$ was examined with low-dose unenhanced protocol. The most relevant ECF and colorectal lesions ( $\geq 6 \mathrm{~mm}$ ) were prospectively assessed according to C-RADS classifications. Follow-up was elaborated based on the electronic record review. Chi-square test was utilized for evaluating the associations between relevant findings and symptoms, age, and sex.

Results: A total of 270 (8.4\%) patients were classified as C-RADS E3, 63 (2.0\%) patients as C-RADS E4, and 437 (13.6\%) patients were assessed with colorectal lesions (CRADS C2-4). At follow-up, two thirds of ECF turned out to be a malignancy or relevant disease that required further medical attention. The proportion of ECF was not related to specific colorectal symptoms. Patients aged $\geq 65$ years and men had significantly higher proportions of ECF than younger patients (C-RADS E3 $p=0.005$; C-RADS E4 $p<0.001$ ) and women (C-RADS E3 $p=0.013$; C-RADS E4 $p=0.009)$, respectively.

Conclusion: Proportions of relevant ECF and colorectal findings are relatively low in symptomatic low-risk patients. By use of CTC as a singular examination,
\end{abstract}

Correspondence to: P. C. G. Simons; email: psimons@viecuri.nl especially in elderly patients, most colonoscopies can be avoided with the benefit of diagnosing relevant ECF without introducing substantial over-diagnosis.

Key words: Extracolonic findings - CT colonography - Virtual colonoscopy - Symptomatic patients - Colorectal cancer-C-RADS
Abbreviations
CTC CT colonography
C-RADS CT Colonography Reporting and Data Sys- tem
ECF Extracolonic findings

CT colonography (CTC) has elaborately been proved as a valid, less invasive, less costly, and more acceptable examination method to prevent and detect colorectal cancer compared to optical colonoscopy [1-12]. CTC is widely accepted as a colorectal screening modality in asymptomatic adults, but can also be performed in symptomatic patients to exclude colorectal cancer [13]. In our practice, we use CTC not only after incomplete colonoscopy or when colonoscopy is contraindicated [14], but also as a primary diagnostic tool in low-risk patients with colorectal symptoms to exclude colorectal cancer and avoid primary invasive colonoscopy [15]. In contrast to optical colonoscopy, with CTC the entire abdomen including the pelvis and lung bases is imaged. Therefore, extracolonic diseases will occasionally be found, for which the potential burden vs. gain is still subject of debate. Recent studies $[16,17]$ have focused on reproducible grading of unlikely significant but 
incompletely characterized (C-RADS E3) and likely significant (C-RADS E4) ECF in an asymptomatic screening population based on the C-RADS classification system by Zalis et al [18]. There have been prior CTC studies with symptomatic patients, but with smaller populations and inclusion of C-RADS E1 or E2 findings $[19,20]$. Inconsistent classification of ECF can distort their incidence and obscure their potential value to clinical practice. It has been noted that elderly people generally have more ECF, but few if any dedicated studies have evaluated unlikely significant (C-RADS E3) and likely significant (C-RADS E4) ECF related to age $[21,22]$. In particular, associations between specific symptoms and the occurrence of relevant ECF have not yet been analyzed in a large symptomatic cohort [19]. Our study uniquely deals with a large symptomatic patient group undergoing CTC, in which the frequencies of potentially relevant C-RADS E3 and E4 findings as well as colorectal lesions are evaluated. In addition, the associations between frequencies of relevant ECF and colorectal findings on the one hand and colorectal symptoms, age, and sex on the other hand were analyzed.

\section{Methods}

\section{Patient population}

Prior to the start of this retrospective study, permission was granted by the Research Commission of our Medical Centre; specific informed consent was not necessary. Data from patients who were examined by CTC at our medical center between January 1, 2007 and September 15, 2016 were incorporated in this retrospective study $(n=5337)$. Patients were referred by general practitioners $(n=2233)$, gastroenterologists $(n=532)$, and other physicians (mainly internists and surgeons) $(n=443)$. For patients with colorectal symptoms and/or abdominal complaints and a relatively low suspicion of colorectal cancer, CTC was performed, whereas among patients with more concerning symptoms or higher suspicion of colorectal cancer, optical colonoscopy was generally preferred. Furthermore, in elderly patients with comorbidities, on anticoagulation, or with a higher risk of endoscopic complications, CTC was typically chosen. All symptomatic patients [ranked in descending order of severity: (1) rectal bleeding, (2) anemia, (3) changed bowel habits, (4) obstipation, (5) abdominal pain] undergoing first-time CTC were included $(n=3208)$. Among patients with more than one symptom, the most severe symptom was registered, e.g., in the presence of changed bowel habits and abdominal pain, the former was chosen. Patients with known colorectal cancer $(n=290)$, familial predisposition for colorectal cancer $(n=120)$, incomplete optical colonoscopy $(n=533)$, and asymptomatic patients $(n=519)$ were excluded (Fig. 1). Patients referred from other hospitals, for which we do not have access to medical records, were also excluded $(n=667)$.

\section{Assessment of extracolonic classification}

ECF were reported in the CTC report and at the same day the related C-RADS classification according to "Criteria of the established CT Colonography Reporting and Data System (C-RADS)" by Zalis et al (Table 1) [10] were set into the CTC database by the radiologist. For clinical relevance, only "unlikely significant but incompletely characterized" (C-RADS E3) and "likely significant" (C-RADS E4) ECF were used and further considered for this study. ECF that were previously known were also excluded from consideration. In the case of indeterminate organ-based lesions, especially in the liver, kidneys, and ovaries, if there were neither clear signs of benignity nor malignancy, we described this lesion as indeterminate (C-RADS E3). Cystic ovarian lesions were only included in women older than 50 years of age. We considered uncomplicated hernias as C-RADS E2 findings, whereas more complicated hernias were classified as C-RADS E3. Abdominal aortic aneurysms $3-5 \mathrm{~cm}$ in diameter were classified as C-RADS E3 and those $>5 \mathrm{~cm}$ as C-RADS E4. Similarly, iliac aneurysms $<2.5 \mathrm{~cm}$ were classified as C-RADS E3 and $>2.5 \mathrm{~cm}$ as C-RADS E4; splenic and renal artery aneurysms $<2.0 \mathrm{~cm}$ were C-RADS E3 and $>2.0 \mathrm{~cm}$ were C-RADS E4. In cases of primary cancer with metastatic disease, the primary tumor was classified as C-RADS E4, but the metastases or other secondary complications were not separately considered. In patients with more than one C-RADS E3 or E4 finding, or a combination of C-RADS E3 and E4 findings, the most severe ECF was chosen for final analysis.

\section{Follow-up of ECF}

The median follow-up period was 5.6 years $(\mathrm{SD} \pm 2.3)$ with a range of 8 months until 10 years. In all patients classified with at least one C-RADS E3 or E4 ECF, follow-up was executed based on the internal hospital electronic medical data system. Follow-up consideration included the evaluation of inpatient or outpatient clinical care and radiological, surgical, and pathologic work-up. Colorectal findings at CTC were also recorded. Patients were classified as "no surveillance or evaluation done" when there was no continuative documentation about ECF in the electronic medical data system, refused treatment due to personal reasons or old age, or if there was no successive referral for medical evaluation. Follow-up data were subdivided into "benign diagnosis: no treatment required," "malignancy" (primary tumor or metastatic disease), and "other conditions: surveillance or treatment required." Benign diagnosis implied, for example, pulmonary hamartoma, simple hepatic, renal or ovarian cysts, liver hemangioma, or lymphadenopathy without clinical relevance. 


\section{CT colonography technique}

In all patients, bowel preparation consisted of a low-fiber diet for $48 \mathrm{~h}$, with $150 \mathrm{~mL}$ magnesium citrate in the morning and bisacodyl $10 \mathrm{mg}$ in the morning as well as in the evening on the day before CTC. Fecal tagging was used with $225 \mathrm{~mL}$ barium sulfate $(49 \mathrm{mg} / \mathrm{mL}$ diluted in $1 \mathrm{~L}$ of water) ingested the evening before the examination. CTC was performed by trained technicians using a 64-slice MDCT scanner (Brilliance 64, Philips Healthcare, Best, The Netherlands) or a 128-slice MDCT scanner (Somatom, Siemens, Erlangen, Germany), imaging in both supine and prone positions with low-dose standard protocol, $120 \mathrm{kV}$ and $50 \mathrm{~mA}$ with dose modulation, and section thickness $1 \mathrm{~mm}$. When mobility was restricted, patients were examined in the left and right decubitus positions. Colonic distension was achieved by administering $1 \mathrm{~mL}$ scopolamine butyl $20 \mathrm{mg} / \mathrm{mL}$ and subsequently automated low-pressure delivery of carbon dioxide $\left(\mathrm{PROTOCO}_{2} \mathrm{~L}\right.$, Bracco Diagnostics, Monroe Townships, NJ). In most cases, no intravenous contrast medium was used; for a minority of cases, intravenous contrast was administered $(n=105 / 3208$; $3.3 \%)$. ECF were evaluated in supine axial, sagittal, and coronal reconstructions using lung, soft tissue, and bone window settings. Colorectal findings were evaluated using a dedicated workstation (Extended Brilliance Workspace, Philips Healthcare; Best, The Netherlands) using a 3D analysis with endoview, filet view, and computer-assisted detection, in addition to the traditional 2D review. Colorectal findings were also classified according to C-RADS classification [10].

\section{Data analyses}

Data analyses were performed with Statistical Package for the Social Sciences (SPSS) version 22. Proportions and percentages of C-RADS E3 and E4 findings and colorectal lesions $\geq 6 \mathrm{~mm}$ (C-RADS C2-4) were calculated. Associations between C-RADS E3, E4 findings, or colorectal lesions, on the one hand, and colorectal symptoms, age, and sex, on the other hand, were evaluated with the Chi-square test.

\section{Results}

After all exclusions, a total of 3208 symptomatic patients (men $n=1271$, women $n=1937$; mean age 62.9, SD $\pm 13.7)$ investigated with CTC from January 2007 until September 2016 comprised the study cohort (Fig. 1). In 270 of 3208 patients $(8.4 \%)$ C-RADS E3 and in 63 of 3208 patients (2.0\%) C-RADS E4 (Fig. 2) ECF were found. A total of 24 patients had more than one C-RADS E3 finding and 4 patients had more than one C-RADS E4 finding. Ten patients had both C-RADS E3 and C-RADS E4 findings. In 60 of 3208 (1.9\%), no surveillance or evaluation was executed.
A total of $437 / 3208(13.6 \%)$ patients had at least one colorectal lesion $\geq 6 \mathrm{~mm}$, of whom $96 / 3208$ (2.8\%) had a colorectal malignancy. Of these 96 patients diagnosed with primary colorectal cancer, $16 / 3208(0.5 \%)$ patients had metastatic colorectal disease. In 2771 of 3208 (86.4\%) patients, colorectal lesions could be excluded without the use of optical colonoscopy.

A total of 59/3208 (1.8\%) patients had both relevant ECF and colorectal findings.

After follow-up assessment, 112/3208 (3.5\%) patients who had primarily been classified at CTC with at least one C-RADS E3 finding (Table 2) and 30/3208 (0.9\%) patients primarily classified with at least one C-RADS E4 finding (Table 3) had clinically relevant disease where further medical care was required. Of these, 16/3208 (0.5\%) patients with C-RADS E3 findings and 23/3209 $(0.7 \%)$ with C-RADS E4 findings turned out to have malignant disease (Table 4).

In patients in whom evaluable follow-up was done, 90 of $218(41.3 \%)$ patients had benign diagnosis and 128 of $218(58.7 \%)$ had relevant non-malignant or malignant disease in the C-RADS E3 category. In the C-RADS E4 category, 3 of $56(5.6 \%)$ patients had benign diagnosis and 53 of $56(94.6 \%)$ had relevant non-malignant or malignant disease. In total, 93 of 274 (33.9\%) patients had benign diagnosis and 181 of $274(66.1 \%)$ had relevant non-malignant or malignant disease.

There was no significant association between colorectal symptoms and proportion of C-RADS E3 findings $(p=0.657)$ or C-RADS E4 findings $(p=0.146)$ (Table 5). In contrast, patients with either rectal blood loss or anemia had a significantly higher proportion of at least one colorectal lesion $\geq 6 \mathrm{~mm}(p<0.001)$ than patients with other colorectal symptoms.

Patients older than 65 years had significantly more C-RADS E3 and E4 findings than younger patients [CRADS E3 $149 / 1507 \quad(9.9 \%)$ vs. $121 / 1701 \quad(7.1 \%)$, $p=0.005 ;$ C-RADS E4 $49 / 1507$ (3.3\%) vs. $14 / 1701$ $(0.8 \%), \quad p<0.001]$. Similarly, patients older than 65 years more frequently had at least one colorectal lesion $\geq 6 \mathrm{~mm}(266 / 1507 ; 17.7 \%)$ than younger patients $(171 / 1701 ; 10.1 \% ; p<0.001)$.

Men had significantly more relevant ECF than women [C-RADS E3 126/1271 (9.9\%) vs. 144/1937 (7.4\%), $p=0.013$; C-RADS E4 $35 / 1271(2.8 \%)$ vs. $28 / 1937$ (1.4\%), $p=0.009$ ] and more colorectal lesions $\geq 6 \mathrm{~mm}$ than women [men 205/1271 (16.1\%) vs. women 232/1937 $(12.0 \%), p=0.001]$.

\section{Discussion}

CTC is a less invasive and more acceptable examination tool compared to optical colonoscopy to exclude colorectal cancer. ECF in CTC, however, is a controversial topic and it remains contestable whether the possible benefits of diagnosing relevant extracolonic disease in 


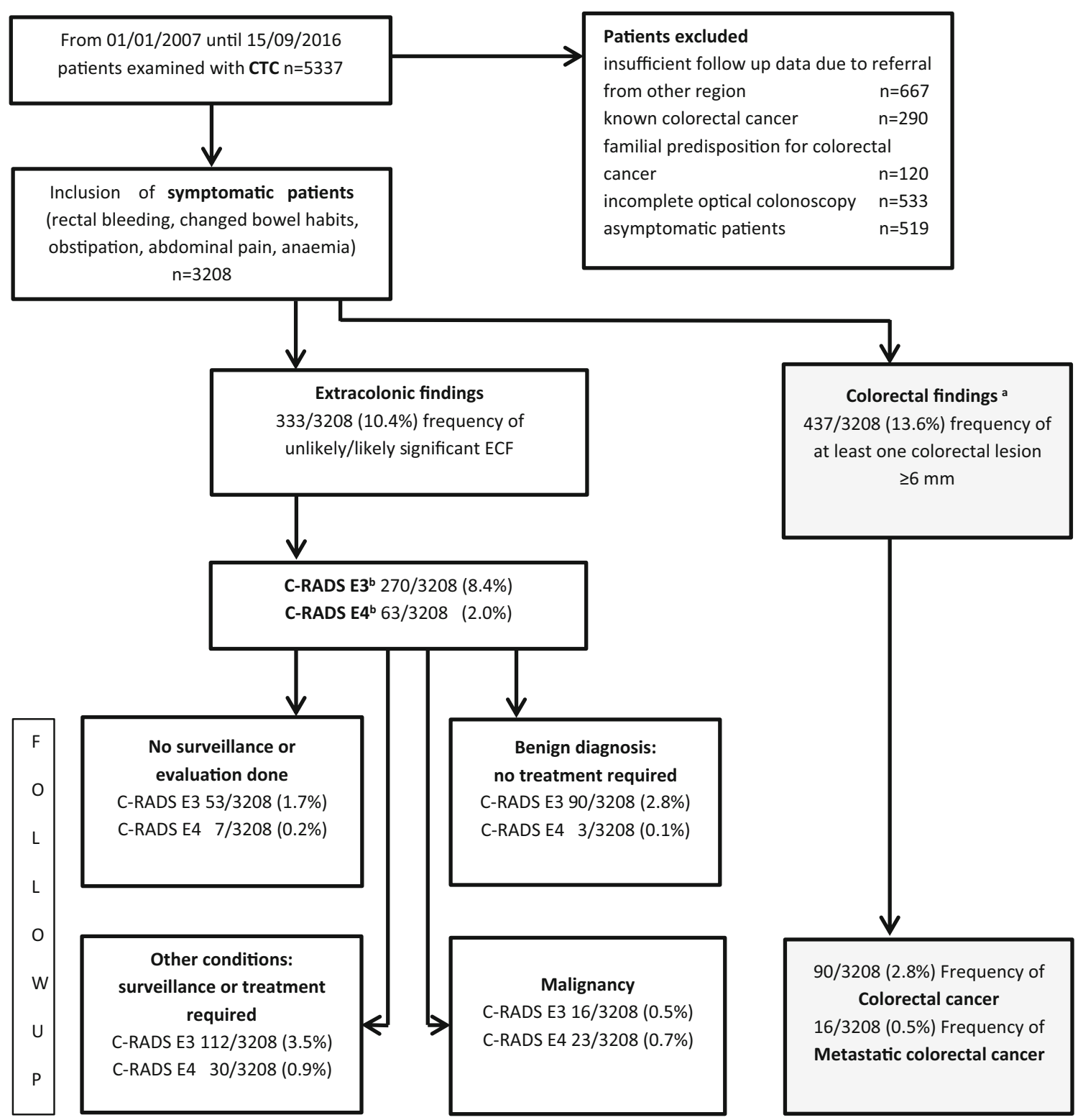

Fig. 1. Selection process and follow-up of relevant ECF in symptomatic patients. ${ }^{\mathrm{a}} 59$ patients had at least one ECF and one colorectal lesion. ${ }^{b} 24$ patients had more than one C-RADS E3 and 4 patients had more than one C-RADS E4 findings. There were 10 patients having both, C-RADS E3 and E4, findings. In the flowchart, only one ECF per patient, the most severe, was analyzed. Therefore, patients had either one C-RADS E3 finding or one C-RADS E4 finding.

Table 1. Classification for ECF detected on CTC using the C-RADS criteria adapted from Zalis et al. [10]

\begin{tabular}{|c|c|c|}
\hline Classification & Description & Example(s) \\
\hline E0 & $\begin{array}{l}\text { Assessment of extracolonic soft tissues limited due to } \\
\text { poor-quality CTC study }\end{array}$ & Limitation produced by artifacts such as metallic implants \\
\hline E1 & $\begin{array}{l}\text { Variants in anatomy. Not likely to influence the } \\
\text { patient's health status }\end{array}$ & Circumaortic left renal vein \\
\hline E2 & $\begin{array}{l}\text { ECF of low clinical importance. Further patient's } \\
\text { work-up not required/unlikely required }\end{array}$ & $\begin{array}{l}\text { Benign cysts (renal, hepatic, or splenic) } \\
\text { Degenerative vertebral changes } \\
\text { Gallstones or kidney stones without related complications }\end{array}$ \\
\hline E3 & $\begin{array}{l}\text { Indeterminate or incompletely characterized ECF. } \\
\text { Subject to local practice work-up may be indicated }\end{array}$ & $\begin{array}{l}\text { Complex or homogenously hyperattenuating lesion } \\
\text { Pleural effusions, bronchiectasis }\end{array}$ \\
\hline E4 & $\begin{array}{l}\text { ECF of clear or potential significance. Work-up or } \\
\text { treatment indicated and communication to refer- } \\
\text { ring clinician essential }\end{array}$ & $\begin{array}{l}\text { Solid organ malignancy, large aneurysms } \\
\text { Lymphadenopathy }\end{array}$ \\
\hline
\end{tabular}




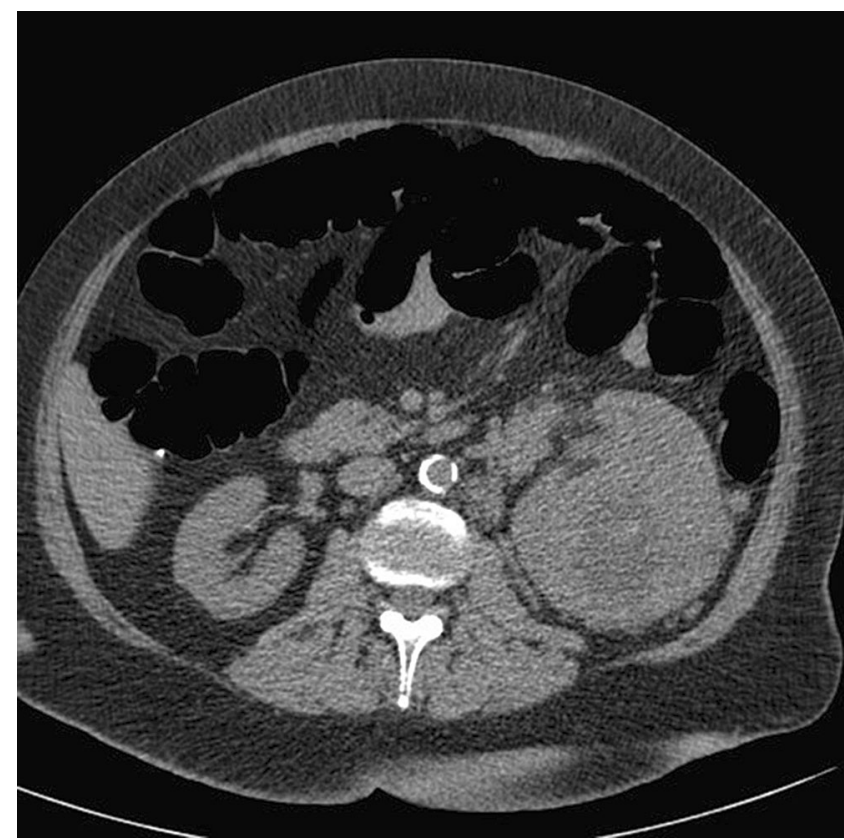

Fig. 2. A 64-year-old female patient presented with unexplained abdominal discomfort. CT colonography showed two small polyps of $6 \mathrm{~mm}$ in the colon and as extracolonic finding a huge pathologic mass in the left kidney (E4). Follow-up revealed renal cell carcinoma without metastases.

Table 2. Number of patients with non-malignant ECF classified as C-RADS E3 on CTC in whom at follow-up pathologic finding was confirmed and treatment or surveillance was necessary

\begin{tabular}{lc}
\hline Type of non-malignant disease & Numbe \\
\hline Abdominal aortic aneurysm $3-5 \mathrm{~cm}$ & 31 \\
Complicated hernia & 18 \\
Urolithiasis & 11 \\
Iliac $(<2.5 \mathrm{~cm}) /$ splenic/renal $(<2 \mathrm{~cm})$ artery aneurysm & 7 \\
Bronchiectasis/atelectasis & 7 \\
Ovarian fibrothecoma/cystadenoma & 5 \\
Pneumonia & 4 \\
Pancreatitis/pancreatic cyst & 4 \\
Adrenal adenoma & 4 \\
Congestive heart failure & 3 \\
Paget's disease & 3 \\
Inflammatory process appendix & 3 \\
Inflammatory bowel disease & 2 \\
Others & 10 \\
\hline
\end{tabular}

${ }^{a}$ Sarcoidosis, kidney failure, endometriosis, pelvic congestion syndrome, mesenteric vascular occlusion, bone fractures

symptomatic patients outweigh the disadvantage of diagnosing irrelevant findings leading to anxiety of the patients and costs of additional examinations.

Our study demonstrated in a low-risk symptomatic population that the proportion of C-RADS E3 (unlikely significant but incompletely characterized) and C-RADS E4 (likely significant) ECF diagnosed at CTC was low, i.e., $8.4 \%$ and $2.0 \%$, respectively. At follow-up, the majority of these patients (66\%), however, turned out to have relevant or even malignant extracolonic disease.
Table 3. Number of patients with non-malignant ECF classified as C-RADS E4 on CTC in whom at follow-up pathologic finding was confirmed and treatment or surveillance was necessary

\begin{tabular}{lc}
\hline Type of non-malignant disease & Numbe \\
\hline Urinary bladder retention & 8 \\
Abdominal aortic aneurysm $>5 \mathrm{~cm}$ & 5 \\
Iliac $(>2.5 \mathrm{~cm}) /$ splenic/renal $(>2 \mathrm{~cm})$ artery aneurysm & 5 \\
Ureteropelvic junction obstruction & 2 \\
Crohn's disease & 2 \\
Ovarian teratoma & 2 \\
Others $^{\mathrm{a}}$ & 6 \\
\hline
\end{tabular}

${ }^{a}$ Pneumonia, renal angiomyolipoma, complicated diverticulitis, aortic stenosis

Table 4. Malignancy found at CTC

\begin{tabular}{lc} 
& Number \\
\hline Primary malignancy & \\
Renal cell carcinoma & 9 \\
Lung carcinoma & 6 \\
Pancreatic carcinoma & 3 \\
Gastric/oesophageal carcinoma & 3 \\
Urothelial carcinoma & 2 \\
Ovarian carcinoma/non-Hodgkin's & 3 \\
lymphoma/sarcoma & \\
Metastatic disease & \\
Peritoneal carcinomatosis (Ovarian/endometrial/pancreatic & 5 \\
carcinoma/mesothelioma) & \\
Osseous (Breast/prostate carcinoma, unknown) & 2 \\
Pulmonary (Breast carcinoma) & 2 \\
Hepatic/lymphatic (Pulmonary carcinoma, squamous cell & 2 \\
carcinoma) &
\end{tabular}

a Primary cancer diagnosis was established during follow-up due to metastasis at CTC

Therefore, unnecessary work-up that eventually leads to benign disease of low clinical relevance is limited. The proportion of ECF was significantly higher in older patients and men.

Similarly, the proportion of colorectal findings $\geq 6 \mathrm{~mm}$ was also low in this low-risk patient population (13.6\%). Despite significantly higher proportions of colorectal findings in older patients (18\%) and men (16\%) in our study and prior studies [13,22], in the majority of the patients (86\%) relevant colorectal findings can be excluded and optical colonoscopy can be avoided. Especially, this is of benefit in old and fragile patients. Furthermore, the proportions of ECF were not related to colorectal symptoms, but colorectal lesions were significantly higher among patients with rectal blood loss and anemia.

Our study shows lower proportions of ECF than prior publications in smaller cohorts of symptomatic patients [13, 19, 20, 23-27] reporting rates of "ECF" between $23 \%$ and $65 \%$, however, without using C-RADS classification. In our analysis, we intentionally excluded C-RADS E1 and E2 findings because the assessment of C-RADS E1 and E2 findings is not relevant since no further specific follow-up is recommended due to low 
Table 5. ECF and colorectal findings related to colorectal symptoms, age, and sex

\begin{tabular}{|c|c|c|c|c|}
\hline & Total & $\begin{array}{l}\text { Patients with at least } \\
\text { one C-RADS E3 } \\
\text { finding }\end{array}$ & $\begin{array}{l}\text { Patients with at least } \\
\text { one C-RADS E4 } \\
\text { finding }\end{array}$ & $\begin{array}{l}\text { Total number of patients with } \\
\text { at least one colorectal } \\
\text { lesion } \geq 6 \mathrm{~mm}\end{array}$ \\
\hline \multicolumn{5}{|l|}{ Colorectal symptom } \\
\hline Rectal blood loss & 282 & $23(8.2 \%)$ & $5(1.8 \%)$ & $70(24.8 \%)^{b}$ \\
\hline Anemia & 313 & $31(9.9 \%)$ & $11(3.5 \%)$ & $73(23.3 \%)^{b}$ \\
\hline Changed bowel habits & 903 & $81(9.0 \%)$ & $18(2.0 \%)$ & $121(13.4 \%)$ \\
\hline Obstipation & 194 & $18(9.3 \%)$ & $6(3.1 \%)$ & $21(10.8 \%)$ \\
\hline Abdominal pain & 1516 & $117(7.7 \%)$ & $23(1.5 \%)$ & $152(10.0 \%)$ \\
\hline$p$ value & & $0.657^{\mathrm{a}}$ & $0.146^{\mathrm{a}}$ & $<0.001^{\mathrm{a}}$ \\
\hline \multicolumn{5}{|l|}{ Age group } \\
\hline$<65$ & 1701 & $121(7.1 \%)$ & $14(0.8 \%)$ & $171(10.1 \%)$ \\
\hline$>65$ & 1507 & $149(9.9 \%)$ & $49(3.3 \%)$ & $266(17.7 \%)$ \\
\hline$p$ value & & 0.005 & $<0.001$ & $<0.001$ \\
\hline \multicolumn{5}{|l|}{ Sex } \\
\hline Men & 1271 & $126(9.9 \%)$ & $35(2.8 \%)$ & $205(16.1 \%)$ \\
\hline Women & 1937 & $144(7.4 \%)$ & $28(1.4 \%)$ & $232(12.0 \%)$ \\
\hline$p$ value & & 0.013 & 0.009 & 0.001 \\
\hline
\end{tabular}

$p$ value $<0.05$ was considered significant

${ }^{a}$ Overall $p$ value for any difference in the prevalence of C-RADS E3 resp. C-RADS E4 resp. at least one colorectal lesion between groups with different colorectal symptoms

${ }^{\mathrm{b}} p$ value for the difference in the prevalence of at least one colorectal lesion between patients with the colorectal symptom and patients with all other symptoms

clinical relevance. Halligan et al. [19] and Badiani et al. [20] showed in comparison to our findings a higher proportion of ECF, i.e., $18 \%-23 \%$ for C-RADS E3 and 4.5\%-7\% for C-RADS E4 findings. The patient population in Halligan et al. [13, 19] might have been at higher risk on average compared with our patient population, due to the randomization for optical colonoscopy and CTC in that trial. Badiani et al. [20] assessed ECF, such as uncomplicated hernia and fatty liver, as C-RADS E3 findings, but we classified those findings as C-RADS E2, what leads to some disagreement with our classification. Against this background, there are still some limitations of the C-RADS classification system, because assessment still allows broad latitude for interpretation $[19,26]$ and there will always be some degree of subjective classification. To simplify future research, a more detailed C-RADS guideline for ECF could be useful. Furthermore, we excluded disease patterns that are related to each other and multiple findings within a single patient, which artificially elevates the rates. The methodology we used provided clear results of the incidence of relevant ECF without confusion caused by simply reporting all ECF that were found. As a consequence, we reported lower frequencies of ECF in symptomatic patients than those reported in prior studies.

Interestingly, our proportions of relevant ECF approach the results recently published by Pooler et al [16, 17], demonstrating low rates of ECF classified as C-RADS E3 (9.1\%) and E4 (2.5\%) in a large asymptomatic screening population. Pooler et al stated that only less than $10 \%$ of the C-RADS E3 findings were proved to be clinically significant [16], whereas in $68 \%$ of the C-RADS E4 findings clinical significance was confirmed [17]. In our study, we eventually demonstrated higher rates of clinically relevant ECF, presenting at follow-up in 59\% of patients with C-RADS E3 and in 95\% of patients with C-RADS E4 clinically significant extracolonic disease. As a result, in the minority of patients with possible relevant ECF diagnosed at CTC, unnecessary work-up that might have caused a negative effect was conducted.

As expected, in our study, more concerning colorectal symptoms, such as rectal blood loss and anemia, were associated with higher proportions of colorectal findings. In contrast, colorectal symptoms and even abdominal pain do not significantly influence the rate of ECF, reflecting that the adequate examination tool was chosen. In cases of suspicion of abdominal non-colonic pathology, many patients were presumably not imaged with CTC, but rather examined with other imaging techniques, such as standard CT or ultrasound. This strategy might demonstrate that we have assessed a low-risk cohort with high concordance rates of ECF in asymptomatic patients.

The significantly higher rates of relevant ECF in patients older than 65 years and men meet expectations. Increasing incidence of ECF and colorectal findings with older age has been reported in earlier studies [19-22]. Prior publications have stated broad acceptance [5-12], cost effectiveness $[4,5]$, and higher diagnostic effectiveness [28], of preferably examining older patients with CTC.

Higher rates of ECF in men in our study might be due to higher prevalence of men-relating disease such as an- 
eurysms, smoking-related diseases, and significant hernias. One prior large study showed that while older men (65-79 years) had a slightly higher rate of C-RADS E3/E4 findings compared with women, the situation was reversed for patients in the age range of 50-64 years [22]. The increasing incidence of extracolonic pathology in older patients, especially in men, might be another argument to adopt the primary diagnostic approach with CTC.

As a critical comment to our study, patients were not standardized to be examined with intravenous contrast medium, as recommended for symptomatic patients in the ESGAR guideline [14]. Intravenous contrast will improve diagnostic accuracy for ECF, but on the other hand elderly patients may be more susceptible for renal insufficiency, and we aimed to minimize burdensome examinations and extra costs.

Although we had a large population in this retrospective study, not all patients with ECF classified as C-RADS E3 and E4 had evaluable follow-up (1.9\%) due to non-response of the referred physician, patient's choice, or probably further examination in another hospital outside of our region and this may result in selection bias.

In conclusion, the proportions of ECF and colorectal findings were low $(10.4 \%$ and $13.6 \%)$ in our low-risk symptomatic patient population, approaching the reported rates in asymptomatic screening populations. Therefore, CTC can be seen as a valid screening option even for symptomatic patients. CTC can diagnose important ECF, of which $2 / 3$ revealed significant pathology. CTC can also exclude relevant colorectal findings to avoid colonoscopy, especially in the elderly. These are arguments to examine patients, especially elderly and men, with relatively low suspicion of CRC or extracolonic disease, primarily with CTC as a singular examination technique.

\section{Compliance with ethical standards}

Funding No funding was received for this study.

Conflict of interest Pickhardt is the co-founder of VirtuoCTC; consultant for Bracco and Check-Cap; and shareholder in SHINE, Cellectar, and Elucent. The other authors declare that they have no conflict of interest.

Ethical approval All procedures performed in studies involving human participants were in accordance with the ethical standards of the institutional and/or national research committee and with the 1964 Helsinki declaration and its later amendments or comparable ethical standards. For this type of study formal consent is not required.

\section{References}

1. Pickhardt PJ, Hassan C, Halligan S, et al. (2011) Colorectal cancer: CT colonography and colonoscopy for detection - systematic review and meta-analysis. Radiology 259(2):393-405

2. Simons PC, van Steenbergen LN, de Witte MT, et al. (2013) Miss rate of colorectal cancer at CT colonography in average-risk symptomatic patients. Eur Radiol 23(4):908-913
3. de Gonzales Berrington, et al. (2010) CT colonography: perforation rates and potential radiation risks. Gastrointest Endosc Clin N Am 20(2):279-291

4. Kumar M, Cash BD (2017) Screening and surveillance of colorectal cancer using CT colonography. Curr Treat Options Gastroenterol 15(1):168-183

5. de Haan MC, Pickhardt PJ, Stoker J (2015) CT colonography: accuracy, acceptance, safety and position in organised population screening. Gut 64(2):342

6. Moawad FJ, Maydonovitch CL, Cullen PA, et al. (2010) CT colonography may improve colorectal cancer screening compliance. Am J Roentgenol 195(5):1118-1123

7. Plumb AA, Boone D, Fitze H, et al. (2014) Detection of extracolonic pathologic findings with CT colonography: a discrete choice experiment of perceived benefits versus harms. Radiology 273(1):144-152

8. Pooler BD, Baumel MJ, Cash BD, et al. (2012) Screening CT colonography: multicenter survey of patient experience, preference, and potential impact on adherence. Am J Roentgenol 198(6):1361-1366

9. Pickhardt PJ (2015) CT colonography for population screening: ready for prime time? Dig Dis Sci 60(3):647-659

10. Hummel JM, Steuten LG, Groothuis-Oudshoorn CJ, et al. (2013) Preferences for colorectal cancer screening techniques and intention to attend: a multi-criteria decision analysis. Appl Health Econ Health Policy. 11(5):499-507

11. Moreno CC, Weiss PS, Jarrett TL, et al. (2016) Patient preferences regarding colorectal cancer screening: Test features and cost willing to pay out of pocket. Curr Probl Diagn Radiol 45(3):189-192

12. Lin OS, Kozarek RA, Gluck M, et al. (2012) Preference for colonoscopy versus computerized tomographic colonography: a systematic review and meta-analysis of observational studies. J Gen Int Med 27(10):1349-1360

13. Atkin W, Dadswell E, Wooldrage K, et al. (2013) Computed tomographic colonography versus colonoscopy for investigation of patients with symptoms suggestive of colorectal cancer (SIGGAR): a multicentre randomised trial. Lancet 381:1194-1202

14. Spada C, Stoker J, Alarcon O, et al. (2015) Clinical indications for computed tomographic colonography: european society of gastrointestinal endoscopy (ESGE) and european society of gastrointestinal and abdominal radiology (ESGAR) guideline. Eur Radiol 25:331-345

15. Peulen JJS, de Witte MT, Friederich P et al. (2010) CT-colonography in symptomatic patients referred by the primary care physician in the Netherlands. Ned Tijdschr Geneeskd 154:1444-1451

16. Pooler BD, Kim DH, Pickhardt PJ (2016) Indeterminate but likely unimportant extracolonic findings at screening CT colonography (C-RADS Category E3): incidence and outcomes data from a clinical screening program. Am J Roentgenol 207(5):996-1001

17. Pooler BD, Kim DH, Pickhardt PJ (2016) Potentially important extracolonic findings at screening $\mathrm{CT}$ colonography: incidence and outcomes data from a clinical screening program. Am J Roentgenol 206:313-318

18. Zalis ME, Barish MA, Choi JR, et al. (2005) CT colonography reporting and data system: a consensus proposal. Radiology 236(1):3-9

19. Halligan S, Wooldrage K, Dadswell E, et al. (2015) Identification of extracolonic pathologies by computed tomographic colonography in colorectal cancer symptomatic patients. Gastroenterology 149:89-101

20. Badiani S, Tomas-Hernandez S, Karandikar S, et al. (2013) Extracolonic findings (ECF) on CT colonography (CTC) in patients presenting with colorectal symptoms. Acta Radiol 54:851-862

21. Macari M, Nevsky G, Bonavita J, et al. (2011) CT colonography in senior versus nonsenior patients: extracolonic findings, recommendations for additional imaging, and polyp prevalence. Radiology 259(3):767-774

22. Pooler BD, Kim DH, Lam VP, et al. (2014) CT colonography reporting and data system (C-RADS): benchmark values from a clinical screening program. Am J Roentgenol 202(6):1232-1237 
23. Ginnerup Pederson B, Rosenkilde M, Christiansen TE, et al. (2003) Extracolonic findings at computed tomography are a challenge. Gut 52(12): 1744-1747

24. Khan KY, Xiong T, McCafferty I, et al. (2007) Frequency and impact of extracolonic findings detected at computed tomographic colonography in a symptomatic population. Br J Surg 94(3):335-361

25. Spreng A, Netzer P, Mattich J, et al. (2005) Importance of extracolonic findings at IV contrast medium-enhanced CT colonography versus those at non-enhanced CT colonography. Eur Radiol 15(10):2088-2095
26. Tolan DJ, Armstrong EM, Chapman AH (2007) Replacing barium enema with CT colonography in patients older than 70 years: the importance of detecting extracolonic abnormalities. Am J Roentgenol 189(5):1104-1111

27. Hellström M, Svensson MH, Lasson A (2004) Extracolonic and incidental findings on CT colonography (virtual colonoscopy). Am J Roentgenol 182(3):631-638

28. Veerappan GR, Ally MR, Choi JH, et al. (2010) Extracolonic findings on CT colonography increases yield of colorectal cancer screening. Am J Roentgenol 95:677-686 